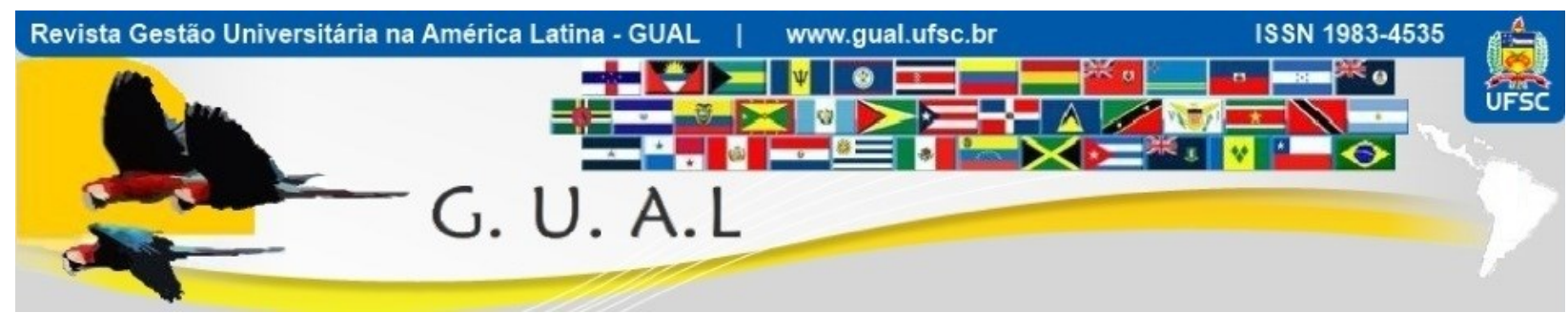

DOI: http://dx.doi.org/10.5007/1983-4535.2015v8n4p200

\title{
PESQUISA EMPÍRICA: MÉTODO PROGRESSISTA PARA DESENVOLVER COMPETÊNCIAS DE LIDERANÇA EM ACADÊMICOS DE CIÊNCIAS CONTÁBEIS
}

\author{
EMPIRICAL RESEARCH: PROGRESSIVE METHOD FOR DEVELOPING \\ LEADERSHIP SKILLS IN STUDENTS OF ACCOUNTING SCIENCES
}

Rosigleide Reboli Cardoso, Mestra Universidade Federal de Rondonia - UNIR gleidecardoso@bol.com.br

Rosana Reboli Cardoso, Graduada Centro Universitário Luterano de Ji-Paraná - CEULJI/ULBRA caixarosana@sicoobcentro.com.br

Ítalo de Paula Casemiro, Mestre Universidade Federal de Rondonia - UNIR itcasemiro@hotmail.com

Jose Moreira da Silva Neto, Doutor Universidade Federal de Rondonia - UNIR msilva@unir.br

Aloir Pedruzzi Junior, Mestre Universidade Federal de Rondonia - UNIR aloir.pedruzzi@unir.br

Valdeson Amaro Lima, Mestre Universidade Federal de Rondonia - UNIR valdeson.lima@ifro.edu.br

Recebido em 05/dezembro/2014

Aprovado em 05/abril/2015

Sistema de Avaliação: Double Blind Review

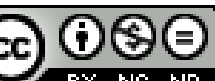

Esta obra está sob uma Licença Creative Commons Atribuição-Uso. 


\title{
RESUMO
}

A necessidade de adequação dos cursos de Ciências Contábeis para entregar ao mercado, profissionais com competências de liderança, capazes de atender as complexidades apresentadas pelas organizações, nortearam este trabalho que teve como objetivo identificar as contribuições da utilização de pesquisa empírica para desenvolvimento de competência de liderança no curso de Ciências Contábeis. Trata-se de uma pesquisa descritiva utilizando os procedimentos estudo de caso e pesquisa bibliográfica, no qual utilizou-se como amostra os acadêmicos do curso de Ciências Contábeis do ano de 2014/01, matriculados na disciplina Liderança Situacional na Atividade Contábil da UNIR. Os resultados da pesquisa permitem afirmar que o método, apresenta-se como ótima alternativa dentre as metodologias de ensino disponíveis aos docentes das áreas humanas nos cursos de Ciências Contábeis, ressaltando-se como suas contribuições, a capacidade de oportunizar a vivência real no contexto das organizações e possibilitar aos acadêmicos, a capacidade de avaliar criticamente os prós e contras dos comportamentos adotados quando no exercício profissional que demandar competências de líderes.

Palavras-chave: Método de ensino. Metodologias de ensino. Liderança. Liderança para contadores. Contador contemporâneo.

\begin{abstract}
The need to adjust the courses in Accounting to deliver to market professionals with leadership skills, able to meet the complexities posed by the organizations, guided this work we aimed to identify the contributions of the use of empirical research to develop leadership competency in Accounting course. This is a descriptive research procedures using case study and literature review, which was used as the sample students of the Accounting year 2014/01 enrolled in the Accounting discipline Situational Leadership Activity of UNITE. The survey results allow us to state that the method is presented as among the great alternative teaching methods available to teachers of humanities courses in Accounting, highlighting how their contributions, the ability to nurture the actual experience in the context of enable organizations and academics, the ability to critically evaluate the pros and cons of behaviors adopted when the professional practice that require skills of leaders.
\end{abstract}

Keywords: Method of teaching. Teaching methodologies. Leadership. Leadership for accountants. Contemporary counter. 


\section{INTRODUÇÃO}

É sabido que as instituições estão se voltando a cada dia para a gestão por competências, onde, os profissionais devem apresentar um rol de conhecimentos, habilidades e valores que deem suporte para que a organização coloque em prática sua Missão e alcance a Visão desejada.

Embora os projetos pedagógicos tenham se equiparado para atender a esse novo contexto, que requer a formação de profissionais de Ciências Contábeis que contemplem competências humanísticas, entende-se que os docentes ainda não estão preparado para atuar no desenvolvimento de tais habilidades, nesta área que prevalece o ensino técnico, pois, ainda predomina a metodologia de aula expositiva e que pouco contribui para o desenvolvimento de habilidades e atitudes, gerando assim, uma frustração nos concluintes (MARION, 2014). O mesmo autor, atribuí essa falha a metodologia utilizada no ensino de Ciências Contábeis.

Em se tratando de competência, vale ressaltar que seus recursos são: conhecimento, habilidade e valores (atitudes). Como é sabido, conhecimentos e habilidades são passíveis de se adquirir por meio de estudo, cursos, capacitações e outros meios de ensino, enquanto valores, são inerentes ao desenvolvimento do indivíduo no que se refere a sua atuação, ou seja, sua escolha de que comportamento/conduta adotar diante das situações (CARBONE et al, 2009).

Os desafios e complexidades impostos à sociedade, mercado de trabalho, organizações e instituições de ensino, requerem que as metodologias de ensino, sejam eficientes e capazes de atender essa necessidade de mercado. A entrega de profissional que apenas entende e executa com perfeição suas atribuições técnicas, já não confere diferencial ao mesmo e as empresas quais fazem parte.

Diante desse cenário, impõe-se às instituições de ensino, avaliar a adequação de suas metodologias com vistas a atender as expectativas da sociedade na formação de profissional com as competências necessárias à geração de produtos e serviços de forma compatível com as mudanças e desafios do novo século.

\subsection{PROBLEMATIZAÇÃO}

O curso de Ciências Contábeis ainda tem apresentado um perfil tecnicista, onde, os acadêmicos ao final da graduação dominam técnicas para auditoria, análises financeiras, escrita fiscal, perícias judiciais ou extra-judiciais relacionadas ao contexto contábil e outros 
(Decreto $n^{\circ} 9295$ de 1946), deixando em segundo plano, o desenvolvimento de habilidades comportamentais que auxilia na sua atuação. Porém, já é ponto pacífico nas discussões em universidades e é ideia amplamente defendida na definição do perfil de contador do século XXI, que este, possua uma formação humanística e visão global para nortear a tomada de decisões coesas, no atual mundo diversificado e complexo, onde é esperado destes profissionais, competências como flexibilidade, liderança, comunicação, visão de futuro e visão humanística.

Com o propósito de trabalhar o conteúdo da disciplina Liderança Situacional para Contadores de forma a atender esse GAP na formação em Contabilidade, o presente estudo buscou identificar as contribuições da utilização de pesquisa empírica para desenvolvimento de competência de liderança no curso de Ciências Contábeis. Teve como objetivos específicos: apresentar resultado da pesquisa empírica realizada pelos acadêmicos e refletir sobre a aprendizagem evidenciada pelos mesmos; relatar a percepção dos graduandos de Ciências Contábeis sobre o método de ensino adotado e; analisar a capacidade dos acadêmicos em desenvolver soluções para atuação em diferentes situações a partir das competências adquiridas na disciplina.

Theóphilo em 1998, já ressaltava a necessidade do emprego da pesquisa empírica na Contabilidade, para que as observações e experimentações possam propiciar a melhoria da teoria e dos modelos contábeis.

O estudo traz como problemática a questão: Quais as contribuições da utilização da pesquisa empírica para desenvolver competência de liderança em acadêmicos de Ciências Contábeis?

\section{REVISÃO BIBLIOGRÁFICA}

A Lei $\mathrm{n}^{\circ} 9.394$ de 20 de dezembro de 1996, que estabeleceu as diretrizes e bases da educação nacional, esclarece em seu artigo primeiro, alínea 2, que a educação escolar, deve alinhar-se ao campo do trabalho, ou seja, o conhecimento ali gerado e disseminado, deve contribuir com a atuação tanto como pessoa e como profissional inserido na sociedade.

A mesma lei, traz em seu artigo 43 a finalidade do ensino superior:

Art. 43. A educação superior tem por finalidade:

I - estimular a criação cultural e o desenvolvimento do espírito científico e do pensamento reflexivo; 
II - formar diplomados nas diferentes áreas de conhecimento, aptos para a inserção em setores profissionais e para a participação no desenvolvimento da sociedade brasileira, e colaborar na sua formação contínua;

III - incentivar o trabalho de pesquisa e investigação científica, visando o desenvolvimento da ciência e da tecnologia e da criação e difusão da cultura, e, desse modo, desenvolver o entendimento do homem e do meio em que vive;

IV - promover a divulgação de conhecimentos culturais, científicos e técnicos que constituem patrimônio da humanidade e comunicar o saber através do ensino, de publicações ou de outras formas de comunicação;

$\mathrm{V}$ - suscitar o desejo permanente de aperfeiçoamento cultural e profissional e possibilitar a correspondente concretização, integrando os conhecimentos que vão sendo adquiridos numa estrutura intelectual sistematizadora do conhecimento de cada geração;

VI - estimular o conhecimento dos problemas do mundo presente, em particular os nacionais e regionais, prestar serviços especializados à comunidade e estabelecer com esta uma relação de reciprocidade;

VII - promover a extensão, aberta à participação da população, visando à difusão das conquistas e benefícios resultantes da criação cultural e da pesquisa científica e tecnológica geradas na instituição.

Num estudo conceitual sobre ensino profissional tem-se a definição de treinamento como sendo um processo de aprendizagem restrito, ou ainda, "à preparação do indivíduo com a assimilação de novos hábitos, conhecimentos, técnicas e práticas voltadas para a satisfação de demandas no exercício da profissão". (Núcleo de estudos sobre trabalho e educação, 2000, apud PACHECO, 2009, p.20).

Pacheco (2009, p.22) salienta que capacitação é:

Ato ou efeito de habilitar, de tornar uma pessoa capaz, possuidora de faculdades, potencial e habilidades para estar em estado de compreender e desenvolver uma determinada atividade. (Núcleo de estudos sobre trabalho e educação, 2000 apud PACHECO, 2009, p.22).

A capacitação torna-se mais eficiente que o treinamento, porém, ainda pouco utilizado pelas organizações em razão de demandar maior tempo e investimento. Esta trata de uma ação continuada e que muitas vezes não atende a necessidade urgente da empresa por determinada qualificação em curto prazo.

Pouco comentada no ambiente empresarial, mas, questão fundamental no mundo científico e razão de ser das instituições de ensino, é a aprendizagem com a finalidade de gerar o desenvolvimento pessoal. Esse desenvolver, se refere a ensinar a pensar, através do fornecimento de condições e estímulos que possibilite ao indivíduo, que ele mesmo encontre as respostas por meio do conhecimento gerado e de sua concepção de certo ou errado, e não, a entrega de uma fórmula do que seria a opção correta. Conforme ideias de Edgar Morin em "Os Sete saberes”, o conhecimento se refere a possibilidade de identificar os erros e ter condições de ver a realidade por seus próprios olhos. 


\subsection{ANDRAGOGIA}

As teorias de marketing argumentam sobre a necessidade de compreender o comportamento do publico alvo para empreender ações que levem a obter mais êxito. $\mathrm{O}$ ensino universitário em sua maioria e composto por pessoas em idade adulta. Isso remete a necessidade de buscar a melhor forma de sensibilizar os alunos, estratégia necessária a qualquer situação que envolva o atendimento satisfatório das expectativas do cliente. Assim sendo, buscou-se na andragogia, ciência que estuda o processo de aprendizagem de adultos, quais são os fatores considerados importantes para envolver este publico, sendo apresentadas por Pacheco (2009), a necessidade de atenção às seguintes premissas:

- Necessidade de conhecer - o adulto só se envolve com os eventos educacionais quando acredita que tal conhecimento é importante para o seu dia a dia.

- Autoconceito - além de possuir a consciência da importância ele é capaz de se autodesenvolver nos assuntos que desejar.

- Experiência - a experiência a ser adquirida é que pode influenciar a participação do mesmo.

- Prontidão para aprender - diz respeito a sua decisão de aprender e não aprender porque é imposto como sua necessidade de aprendizagem.

- Orientação para aprendizagem - a aprendizagem deve ter significado para seu dia a dia e não como receita que poderá ser útil um dia.

- Motivação - o adulto deve buscar/aceitar o conhecimento por desejo próprio e não por estímulos externos.

Este estudo motivou a substituição da metodologia do "aprender ouvindo" através de aulas expositivas, para o "aprender agindo", respeitando um dos princípios da Andragogia, quando se propôs, avaliar o aprendizado adquirido pelo acadêmico através do seu interesse e envolvimento em compreender o tema liderança situacional, entender a pesquisa proposta, aprender a executar a tabulação de dados e que permitiu, a partir de seus conhecimentos e dos resultados levantados em campo, elaborar as conclusões, assumindo assim, a autogestão de seu aprendizado.

A pesquisa científica visa além da geração de conhecimento teórico sobre uma realidade, um contexto, despertar para a busca de respostas para a solução de problemas da sociedade, de uma instituição dentre outras.

Este estudo que buscou no seu objetivo geral identificar as contribuições da utilização de pesquisa empírica para desenvolvimento de competência de liderança no curso de Ciências Contábeis, teve a finalidade de testar meios para sanar a carência apresentada pelo ensino disciplinar, ou seja, que não apresenta conexão entre as disciplinas. Mais do que a aplicação 
de um questionário para avaliar os estilos de liderança presentes nas empresas pesquisadas, o estudo exigiu a utilização do conhecimento pertinente (MORIN, 2000), desenvolvido durante toda a formação universitária, lançando mão da capacidade de colocar o conhecimento (teoria) no contexto (prática).

\subsection{ERA DA CONSCIÊNCIA}

No final do século XX, deu-se inicio a um crescente movimento em defesa à conservação ambiental, como também, aumento nas discussões sobre a estrutura mercantilista predominante até o momento, onde o foco norteador passou do aumento de produtividade (era industrial) para o questionamento do modelo econômico vigente, fruto da necessidade de estabelecer um desenvolvimento sustentável com a congruência da responsabilidade dos governos, das empresas e da sociedade (SROUR, 2013).

Alcançando um patamar mais evoluído de consciência, no que se refere a responsabilidade ativa pelo rumo qual se toma o mundo, as pessoas estão a cada dia, questionando, reivindicando e o mais importante, buscando a qualificação que dê base para cobrar das instituições públicas e privadas, um retorno justo e humano. Essa cobrança e consequentemente valorização do trabalho, se torna mais visível quando relacionada ao trabalho intelectual, modelo qual vem se tornando a atividade desenvolvida pelo profissional contador, possibilitada pela revolução digital. Nesse novo contexto, a atividade deixa de assumir o cunho de trabalho manual qualificado (técnicos de contabilidade), ultrapassando também a era do trabalho manual com execução de rotinas padronizadas (profissional contador dos últimos anos) e ganhando forças para ser reconhecido como trabalho intelectual de concepção criativa (perfil do novo século). Como vem sendo defendido neste artigo, para se equiparar a esta última concepção, o mercado demanda do profissional contador, habilidades de análises para elaboração de projetos, propostas e soluções cada vez mais eficientes para seus clientes e sociedade em geral.

\section{METODOLOGIA}

Essa pesquisa possui natureza aplicada, pois visa conhecer através da bibliografia e dos desdobramentos práticos da proposta para então construir, modificar, ou mesmo apresentar dados a fim de discutir mudanças nos planos de ensino dos cursos de Ciências Contábeis. 
Apresenta abordagem qualitativa com fins descritivos (ANDER, 1978) no ponto que busca descrever os resultados alcançados, utilizando o método indutivo, em pesquisa realizada com graduandos visando identificar as contribuições da utilização de pesquisa empírica para desenvolvimento de competência de liderança no curso de Ciências Contábeis;

O estudo foi realizado no período de março a julho de 2014 e teve como método de procedimento a pesquisa bibliográfica e o estudo de Caso.

A pesquisa bibliográfica tem como característica a investigação e levantamento de teorias através de livros, artigos, teses e outros materiais publicados. Foi utilizada aqui, como meio para fundamentar o contexto de aprendizagem no ensino de graduação e fornecer base para os estudos da Teoria da Liderança e Liderança Situacional II, questão aplicada neste caso.

É classificado como estudo de caso por apresentar como foco a investigação da eficiência do processo de ensino de Liderança Situacional no curso de Ciências Contábeis, utilizando-se de vários procedimentos para coleta de dados, durante um longo período de tempo (CRESWELL, 2010).

\subsection{MÉTODO}

Nas cinco primeiras aulas da disciplina Liderança Situacional na atividade contábil, a pesquisadora, através de aula expositiva, fez a fundamentação teórica sobre Liderança, mais especificamente Liderança Situacional II conforme Blanchard (2007), teoria esta, que fundamentou a pesquisa de campo dos alunos e que serviu de base para desenvolver competências de liderança nos mesmos.

$\mathrm{Na}$ sexta aula, foi apresentado e entregue em formato eletrônico, o material a ser usado pelos alunos, composto por: projeto de pesquisa, instrumento de coleta de dados, instrumento de análise de dados e chave de interpretação dos resultados, conforme metodologia de Blanchard (1988).

No período que compreendeu da sétima a nona aula, os acadêmicos distribuídos em 7 equipes, fizeram a aplicação da pesquisa por meio do instrumento fornecido, em organizações públicas e privadas escolhidas pelos mesmos, seguida da tabulação dos dados e elaboração do trabalho para apresentação dos resultados em sala de aula. 
No período que compreendeu da décima a décima sétima aula foram realizadas as apresentações dos grupos, ficando décima oitava e decima nona aula respectivamente para discussões finais e elaboração dos resultados da pesquisa por esta autora.

O universo considerado neste estudo de caso foi a Universidade Federal de Rondônia, sendo a população, os discentes do curso de Ciências Contábeis, onde a amostra foi composta de 26 alunos concluintes no ano de 2014/01, matriculados na disciplina Liderança Situacional na atividade contábil.

A fim de evidenciar o desenvolvimento de competências de liderança, foi solicitado a realização de trabalho com pesquisa de campo seguida por seminário para apresentação dos resultados, nos quais os acadêmicos usaram para levantamento dos dados em campo, o instrumento de pesquisa LDA de Blanchard (traduzido pela pesquisadora), aplicado aos gestores de empresas públicas e privadas na cidade de Porto Velho, a fim de identificar o estilo de liderança predominante segundo a teoria da Liderança Situacional II, a flexibilidade de estilo e a adaptabilidade. Em razão do questionário já possuir aplicações anteriores, não foi necessário a sua validação.

Os resultados deste estudo de caso foram alcançados através das técnicas de levantamento de dados a saber:

\subsection{COLETA DE DADOS: TÉCNICA 1}

A coleta de dados utilizando a observação sistemática, realizada em sala de aula, através de observação participativa, durante os encontros semanais onde a pesquisadora observou a realização das apresentações dos grupos e registrou o comportamento, as reflexões e as analises críticas sobre o resultado alcançado.

Após a apresentação, cada equipe entregou o material da tabulação dos dados (excel), apresentação em power point e análise crítica sobre o resultado em arquivo eletrônico word.

\subsubsection{Coleta de dados: Técnica 2}

Outra técnica utilizada para coletar dados foi a Discussão em Grupo, que teve como finalidade, identificar através dos posicionamentos, questões como: modelos mentais, atitudes e opiniões que evidenciam as bases do comportamento inerente aos estilos de liderança compreendidos como sendo adequados à atuação profissional contemporânea. Este ambiente permite a manifestação natural dos participantes, sem a preocupação de "manipular" a 
percepção do avaliador sobre suas opiniões e atitudes, pois, conforme Flick (2009), esse tipo de discussão tende levar os participantes a erguerem suas máscaras.

Como vantagem de técnica para coleta de dados, Flick (2009, p. 182) argumenta que "a discussão estimula um debate" servindo como "fontes centrais de conhecimento" evidenciando "atitudes, opiniões e práticas" que corresponde a maneira real conforme manifestadas na vida cotidiana.

Este caso, conforme Flick (2009) é classificado como grupo natural, pois sua formação se deu em razão de outra finalidade diferente da pesquisa, sendo aproveitado o ambiente oportunizado pela disciplina, a compatibilidade das discussões e informações evidenciadas, para somar com a pesquisa. Enquadra-se como grupo real, por ser composto pelos "membros da situação de pesquisa" que "partem de histórias de interações" compartilhadas e demonstram "padrões subjacentes de significados" (FLICK, 183), neste caso, a linha de formação predominante no curso e na instituição de ensino que, é fator norteador de seus comportamentos, contudo, com base no mesmo autor, define-se como grupo heterogêneo por ser composto por discentes que apresentam características distintas como sexo, idade, experiências profissionais e outros. Com relação ao papel do moderador, por se dar em ambiente de aprendizagem, o mesmo assumiu o direcionamento das dinâmicas, interagindo por meio de contenção das discussões e inserção de questões provocativas.

As discussões do grupo possibilitou a coleta, organização de dados e análise através da interpretação pelo pesquisador.

\subsubsection{Coleta de dados: Técnica 3}

$\mathrm{Na}$ decima oitava aula, foi aplicado questionário de reação a fim de avaliar o desempenho da disciplina, bem como, o contexto operacional no qual foi ministrada, buscando evidenciar sinais relativos às oportunidades de melhoria. $\mathrm{O}$ instrumento com escala Likert de 5 pontos e campo para justificativa da resposta, apresentou 4 questões para identificar os indicadores: plano de disciplina; ações empreendidas nas aulas; prontidão do professor; e auto avaliação do discente. Os dados foram tabulados em programa excel e permitiu a elaboração de gráfico para apresentação dos resultados. 


\section{RESULTADOS}

O ensino disciplinar, com bases no pensamento linear já não vem conseguindo gerar resultados inovadores e criativos como métodos de instigar a reflexão e geração de seres pensantes, para fazerem frente às demandas complexas e mudança de paradigmas das entidades modernas, sendo esse um atual desafio para a educação em todos os níveis.

Ainda sobre o ensino através de disciplinas, Morin (2000) ressalta que o atual método de ensino por disciplina, que apresenta o conhecimento de forma fragmentada e dividida, impede a capacidade natural que o espírito tem de contextualizar, apresentando-se como desafio aos docentes, estimular e desenvolver essa capacidade de ligar as partes ao todo e o todo às partes.

Foucault apud Barbosa (2011) defende que as escolas, assim como prisões, quarteis e hospitais, por meio da vigilância, treinam e controlam as condutas e pensamentos.

Buscando aplicar as metodologias da educação moderna, onde, o professor age como facilitador e estimulador da busca do conhecimento e auxilia no processo de correlação entre as disciplinas, possibilitando a compreensão da complexidade das ciências, o método utilizado na disciplina que foi plano de fundo para este estudo de caso, permitiu que, de posse das informações teóricas, instrumento de pesquisa validado e compreensão do processo, os acadêmicos pudessem entender eles mesmos, como é o funcionamento da liderança na vida real. A pesquisa, permitiu essa interação academia-organização e o entendimento da teoria de liderança considerando as nuances, os detalhes muitas vezes não avaliados, mas que explicam a complexidade dos comportamentos das pessoas e outros fatores que tiram a condição linear e lógica cartesiana geralmente empreendida na sala de aula sobre determinada teoria.

Ir a campo pesquisar sobre os estilos de liderança, permitiu compreender de que maneira a idade, o tempo de empresa, o tempo em cargo de liderança, a cultura da empresa e até o gênero, influenciam nos estilos de liderança adotados, deixando a prática de dar a receita, de ensinar a regra, mas oferecendo a liberdade de observar e estimulando a construção do pensamento e conclusões mediante as diversidades e complexidades existentes no ambiente real. O método adotado para o ensino de liderança buscou ir ao encontro da proposta defendida pelo pedagogo e filósofo Paulo Freire, onde os alunos com base no objeto de estudo, criam seu próprio aprendizado, enquadrando como método progressista e fugindo assim do método tecnicista e alienante. 


\subsection{DADOS DA PESQUISA DE CAMPO REALIZADA PELOS ACADÊMICOS:} APRENDIZAGEM EVIDENCIADA

Durante a exposição dos resultados identificados na pesquisa empírica, foram observados os seguintes resultados:

\section{Equipe 1 - pesquisou 5 gestores de empresa privada do ramo de serviços}

financeiros: Foi observado as correlações realizadas pelos acadêmicos sobre a razão dos gestores apresentarem como estilo primário de liderança, o estilo treinador. O grupo argumentou ser inerente a cultura instalada no ramo de atividade, pois essa é uma das habilidades chaves pela qual a empresa mais facilmente atingirá seus resultados, tanto com empregados quanto com o clientes. Numa reflexão mais profunda, o resultado permitiu aos alunos, concluir que, o líder que melhor desenvolver as habilidades de Treinador, terão melhores resultados em instituições nesse ramo de atividade.

O gráfico seguinte, apresenta o tempo no cargo de gestão e os estilos apresentados por cada entrevistado pelo grupo 1 .

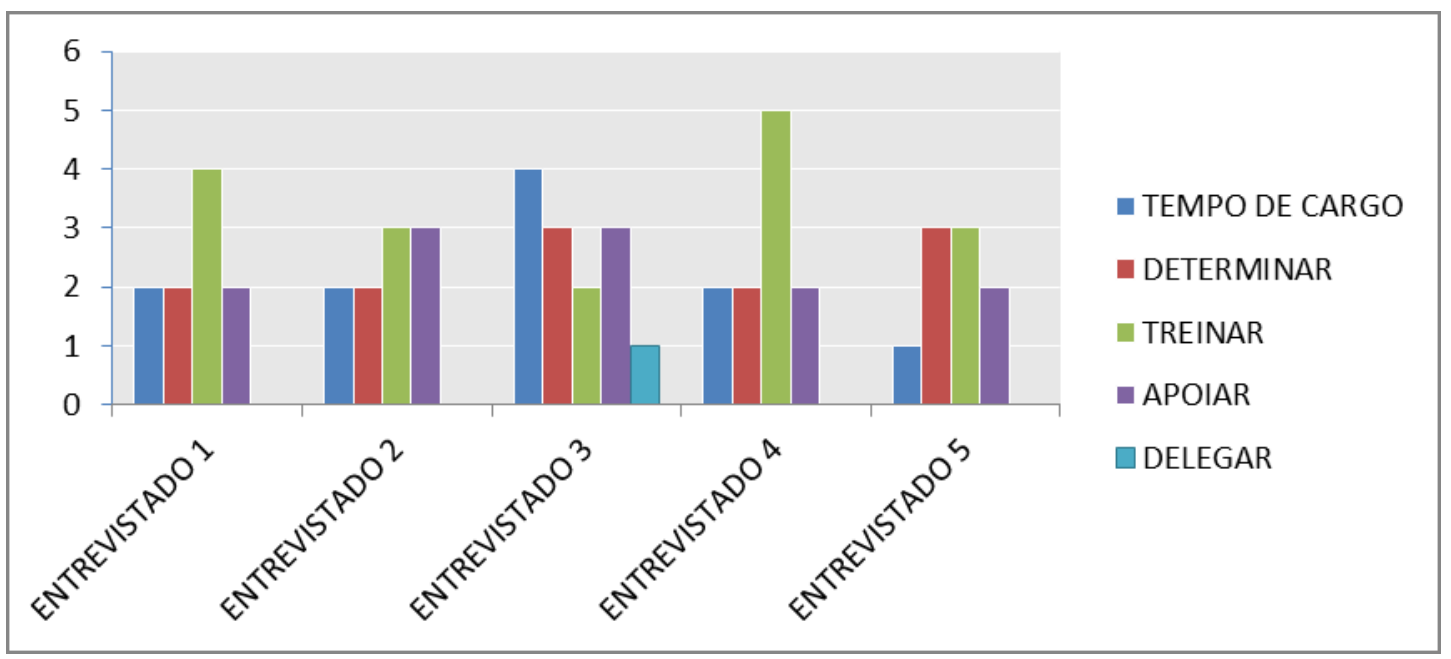

Gráfico 1 Tempo no Cargo X Estilo Principal de Liderança Fonte: Dados da pesquisa realizada pelos acadêmicos

A figura 1, permite compreender que o entrevistado 3 foi o único que apresentou a habilidade de usar a gama de 4 estilos de liderança e é o único que não evidencia a tendência em usar o estilo de Treinar como estilo primário . Na argumentação defendida pela equipe de acadêmicos, esse resultado se justifica devido este entrevistado possuir maior idade dentre os pesquisados e mais tempo em cargo de gestão na empresa que os demais, o que explica a 
maior gama de estilos, a flexibilidade e a segurança deste em conseguir identificar o nível de desenvolvimento dos liderados e moldar seu comportamento de acordo com a demanda.

Equipe 2 - pesquisou 3 gestores de empresa pública da esfera Estadual, setor de fiscalização: $O$ grupo identificou através da pesquisa, que dois dos gestores possuem o estilo de liderança Treinador como predominante e o terceiro possui o estilo Determinador. Os mesmos apresentam boa flexibilidade para usar como estilos secundários o estilo Determinar e Apoiar, não sendo evidenciado o estilo de Delegar em nenhum dos 3 participantes.

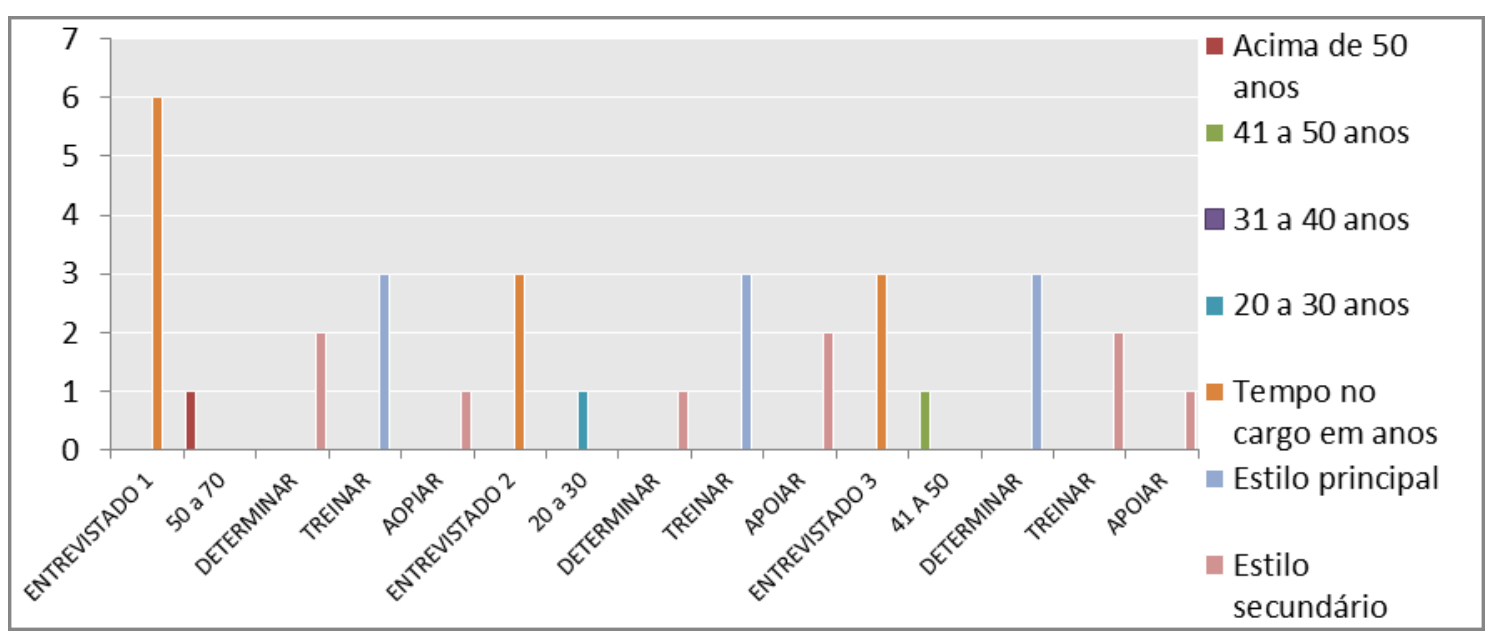

Gráfico 2 Perfil do Gestor X Estilo Principal e Secundário de Liderança Fonte: Dados da pesquisa realizada pelos acadêmicos

Em suas reflexões, a equipe atribuiu a predominância de estilos de liderança com perfil concentrador, em razão da natureza pública da instituição, justificando que, uma abertura maior na gestão dos processos, pode se transformar em não cumprimento das metas, pois, nesse tipo de organização, não há forma de punição por meta não atingida. Dessa maneira, os gestores preferem adotar uma postura mais controladora na execução das tarefas para garantir que as metas sejam cumpridas. Tais conclusões da equipe são subsidiadas pelos dados de idade e tempo de casa e tempo de experiência em gestão que apesar das diferenças, não alteram o estilo de liderança dominante na instituição.

Equipe 3 - Pesquisou 2 gestores de empresa pública da esfera Estadual, sendo a mesma empresa do grupo 2, porém outro setor, aqui o de fiscalização: Os resultados apontam o mesmo cenário que o anterior, apesar das diferenças de idade, tempo de empresa e 
tempo no cargo, os estilos predominantes na organização foram Determinar e Treinar como estilos primários e vice e versa como estilos secundários.

Equipe 4 - pesquisou 4 gestores de empresa pública da esfera Estadual - setor de Segurança: A equipe, encontrou um resultado inesperado e que foge ao padrão apresentado pelas empresas públicas. Três dos pesquisados apresentaram o estilo principal Determinar, enquanto o quarto pesquisado apresentou estilo Compartilhar, sendo que o estilo secundário de todos é o estilo Treinador. O gestor A com a menor idade entre os entrevistados (entre 20 e 30), possui ensino superior e conta com uma equipe de mais de 40 liderados. A equipe concluiu que a variável formação contribui para o desempenho do mesmo, apresentando a capacidade na identificação do melhor estilo a ser usado com cada liderado, alcançando grau de Adaptabilidade moderada.

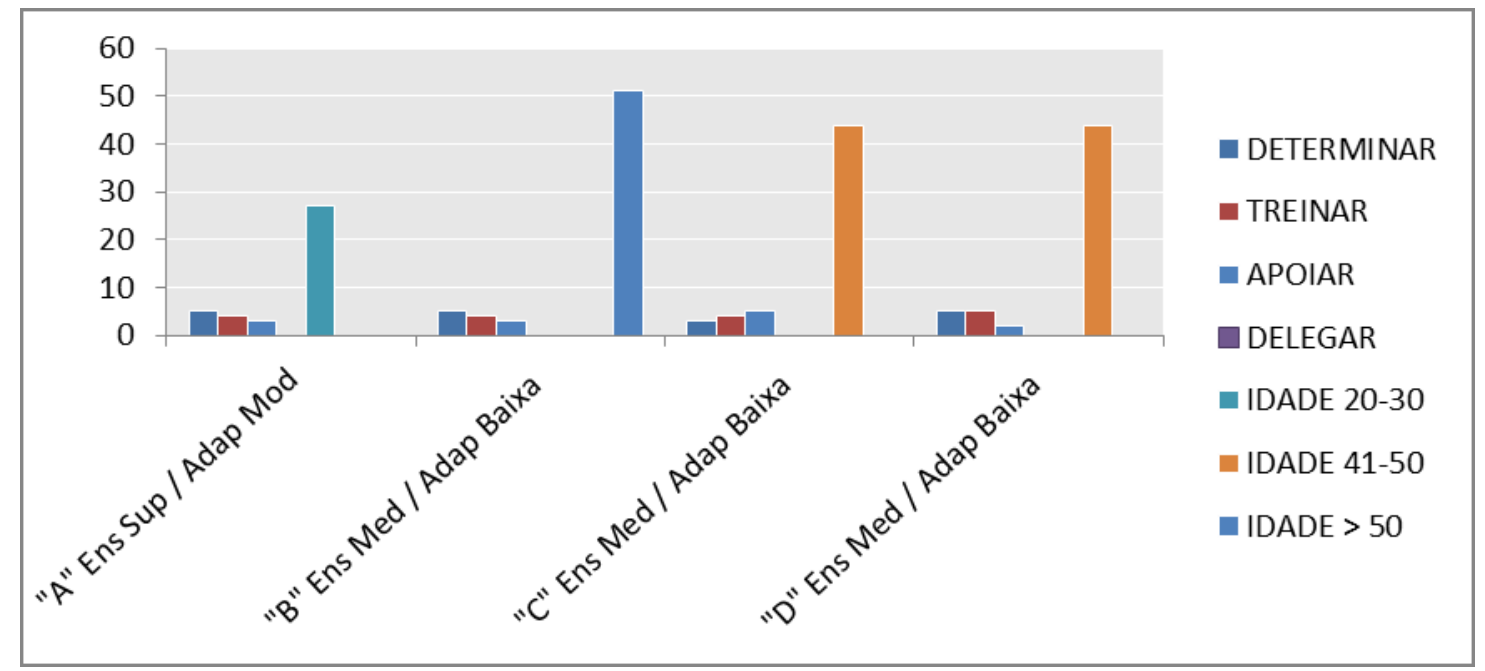

Gráfico 3 Perfil (escolaridade e idade) X Estilo Principal e Secundário X Grau de Adaptabilidade Fonte: Dados da pesquisa realizada pelos acadêmicos

O estilo principal Apoiar do pesquisado C, foi justificado pelo mesmo possuir o maior tempo no cargo de gestão, acima de 6 anos, o que confere a segurança em usar um estilo mais democrático, pois já conhece os liderados, enquanto os outros pesquisados possuem apenas 1 ano no cargo de gestão. A equipe concluiu ainda que, apesar do caráter rígido inerente a instituição militar, é possível e se faz necessário usar estilos de liderança que promovam a participação dos liderados, a fim de envolvê-los para alcance de melhor nível desempenho na equipe. 


\subsection{DISCUSSÃO}

Participaram desse estudo 26 acadêmicos de Ciências Contábeis da turma 2014/1 matriculados na disciplina Liderança Situacional na atividade Contábil. Com base na fundamentação teórica da disciplina e de posse do material de pesquisa composto pelo projeto de pesquisa, instrumento de coleta de dados, instrumento de análise de dados e chave de interpretação dos resultados, os mesmos executaram as pesquisas e apresentaram os resultados que permitiu as reflexões que seguem.

\subsection{DISCUSSÃO E ANÁLISE DOS RESULTADOS: FEEDBACK FORNECIDO PELOS ACADÊMICOS}

Com a preocupação de oferecer um processo de ensino aprendizagem, que faça submergir o que foi realmente aprendido, proporcionando o desenvolvimento de competência, a disciplina de Liderança Situacional na Atividade Contábil, foi conduzida empregando métodos voltados para a reflexão e a prática, e não apenas para a prática memorativa de informações e definições (LEITE e LIMA, 2008 apud SILVA, ANDRADE E NETO, 2012), servindo como plano de fundo para elaboração de pesquisa na área de ensino através de métodos progressistas.

Nos relatos em sala de aula, os acadêmicos foram unânimes em dizer que enquanto metodologia de aprendizagem, a realização da pesquisa empírica, contribuiu mais para a absorção da teoria, do que metodologia de aula expositiva, pois, exigiu um aprofundamento e entendimento claro da Teoria de Liderança Situacional para analise e discussão dos resultados da pesquisa realizada em campo.

Foi apontada como positiva, a oportunidade de vivenciar o contexto das organizações, possibilitando aos mesmos, a capacidade de avaliar criticamente as "angústias" dos lideres e liderados sobre os fatores que envolvem a gestão de tarefas e relacionamentos. Esse fato contribuiu para a compreensão do complexo exercício que é liderar, gerando consciência e responsabilidade nos acadêmicos sobre o rol de competências a serem desenvolvidas pelo profissional, para ser qualificado como líder e não apenas como gestor, chefe ou gerente.

A metodologia levou a uma avaliação holística do contexto avaliado onde ocorreu o fenômeno da liderança, ou seja, as organizações pesquisadas, exigindo a consideração de diversas variáveis para entendimento do estilo de liderança predominante em cada uma das organizações. 
Como conteúdo curricular com abordagem humana e distinto dos demais da grade do curso de Ciências Contábeis, a disciplina contribuiu para o entendimento de que existem várias maneiras de influenciar uma pessoa e que o estilo a ser usado pelo líder deve ser compatível com o nível de desenvolvimento e prontidão do liderado, o que exige do líder, aqui considerando os acadêmicos, um comprometimento constante para desenvolvimento das habilidades e capacidades de identificar o estágio do liderado para a tarefa e, a partir daí, moldar em si o comportamento propício para atingir o melhor nível de desempenho.

Com isso, entende-se que houve contribuição em termos de conhecimento prático no assunto Liderança Situacional. Esse conhecimento prático, permitiu que cada acadêmico identificasse, com base em seus atuais comportamentos, o que é passível de adequação para capacitá-los à aplicação da Liderança Situacional.

\subsection{RESULTADOS DA PESQUISA DE REAÇÃO: AVALIAÇÃO DO MÉTODO}

O questionário aplicado aos acadêmicos no final da disciplina, permitiu avaliar o desempenho e orientar sobre os fatores passíveis de melhoria na disciplina e seu contexto, conforme apresentado no gráfico 5 .

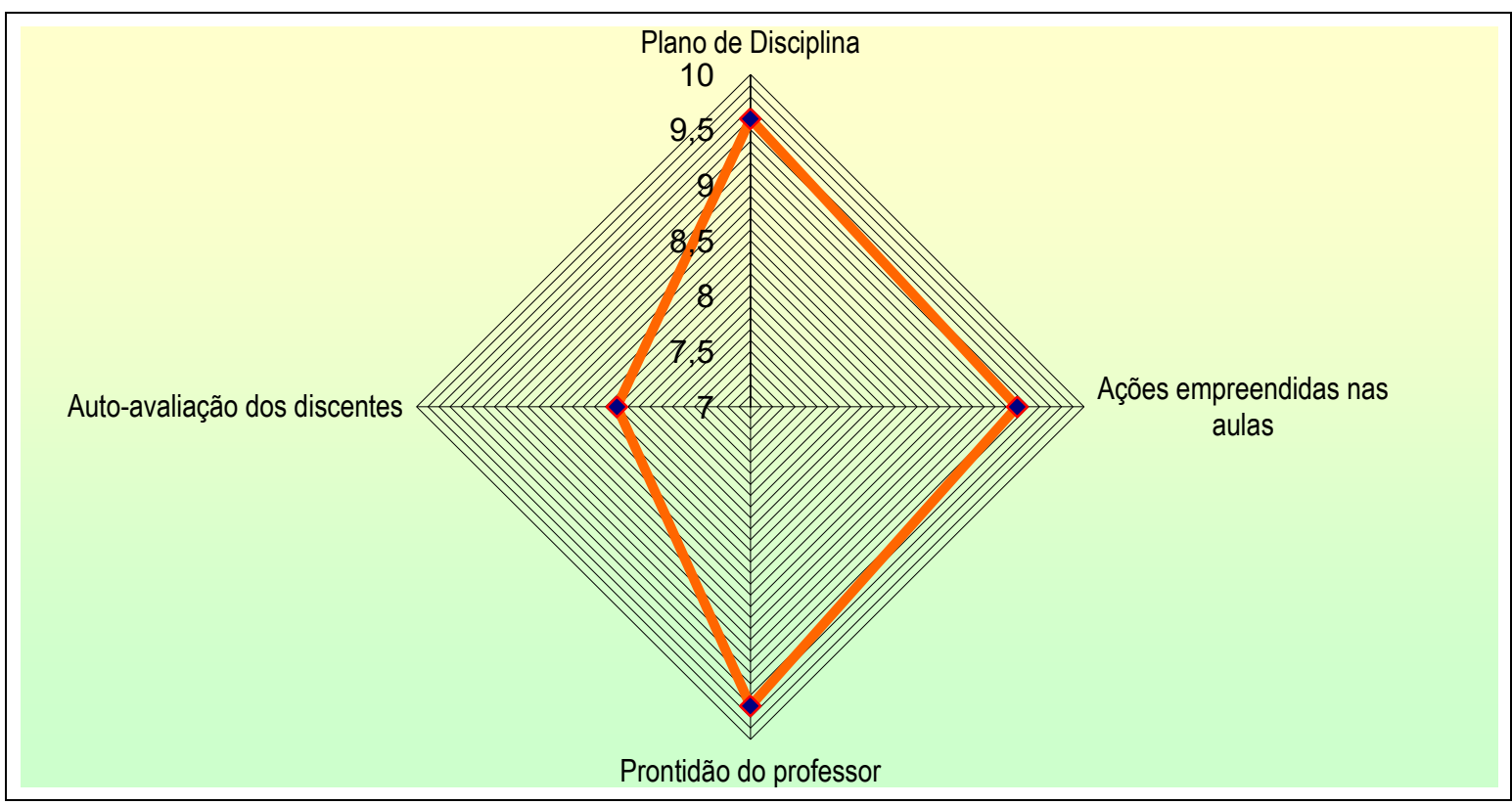

Gráfico 5 Performance da Disciplina LIDERANÇA SITUACIONAL NA ATIVIDADE CONTÁBIL - Semestre $01 / 2014$

Fonte: Dados da pesquisa realizada pela autora

Com relação ao indicador 1 - Plano de disciplina, que evidencia a coerência do plano de ensino com o aprendizado objetivado, obteve-se a nota 9,6 e justificativas com os seguintes 
depoimentos: "houve grande aprendizado"; "conseguimos ter entendimento sobre liderança e os tipos de lideres para aplicação no trabalho"; "o plano proposto foi evidenciado e praticado através das atividades de campo".

A questão para investigar o indicador 2 - Ações empreendidas nas aulas, obteve nota 9,4 e apontou comentários como: "foi visto o conteúdo planejado de forma satisfatória e produtiva"; "as atividades a todo o tempo buscaram mostrar o papel da liderança";

O indicador, Prontidão do Professor, obteve nota 9,7 e os comentários: "foi essencial facilitando o aprendizado com dinamismo"; "atuou com desenvoltura"; "sempre esteve a disposição para esclarecimentos".

E por último, o quesito: Auto avaliação do discente, apresentou nota 8,2, obtendo os seguintes depoimentos: "Estive participante em todas as aulas que assisti"; "em alguns momentos houve desvio de atenção"; "em algumas aulas não me preparei o suficiente"; "participei das atividades propostas dentro de minhas limitações".

\section{CONCLUSÃO}

Pesquisas empíricas no campo organizacional são desenvolvidas a fim de investigar as causas e buscar soluções capazes de promover a competitividade e crescimento das mesmas.

A competência das pessoas que constituem estas organizações, aqui em especial os profissionais contadores, apresenta-se como fatores fundamentais, capazes de conferir tal sucesso às organizações, pois não se concebe desenvolvimento organizacional, se não por meio do desenvolvimento das pessoas. E este sucesso está atrelado a capacidade de atender as demandas, que, em constante mudanças e aumento no grau de complexidade, se apresentam no cenário mundial.

A fim de gerar conhecimento para contribuir com esses desafios este estudo teve como problema investigar quais as contribuições da utilização da pesquisa empírica para desenvolver competência de liderança em acadêmicos de Ciências Contábeis.

Após a apresentação dos resultados da pesquisa empírica realizada pelos acadêmicos e, com base na aprendizagem evidenciada pelos mesmos, foi possível a conscientização sobre os diversos estilos de liderança existentes conforme a teoria da liderança situacional como também os diferentes níveis de desenvolvimento encontrados em um profissional e a necessidade do reconhecimento desse fator para seleção do estilo de liderança adequado a ser utilizado com este. As pesquisas e discussões possibilitaram o entendimento de que não existe 
um estilo de liderança considerado melhor e sim, vários, devendo o gestor, desenvolver a capacidade de compreensão de cenários e identificação do desenvolvimento individual de cada integrante de sua equipe para escolha do estilo correto para a situação.

Com relação ao objetivo de relatar a percepção dos graduandos de Ciências Contábeis sobre o método de ensino adotado, os acadêmicos foram unânimes em dizer que enquanto metodologia de aprendizagem, a realização da pesquisa empírica, contribuiu mais para a absorção da teoria, do que metodologia de aula expositiva, pois, exigiu um aprofundamento e entendimento claro da Teoria de Liderança Situacional para analise e discussão dos resultados da pesquisa realizada em campo, levando a pesquisadora concluir que, os alunos tiveram grande envolvimento na execução das atividades, assumindo para si a responsabilidade de compreender o conteúdo da disciplina. Essa compreensão alcançada permitiu o uso do conhecimento numa visão global, no sentido de relacionar os resultados alcançados em campo à complexidade dos ambientes organizacionais pesquisados.

Quanto ao objetivo de analisar a capacidade dos acadêmicos em desenvolver soluções para atuação em diferentes situações a partir das competências adquiridas na disciplina, a pesquisadora considera que, as reflexões realizadas durante as exposições contribuiu para o aumento da visão global dos acadêmicos, o que permite avaliar a consequência de cada estilo de liderança em diversas situações e identificar a necessidade de desenvolvimento pessoal desse lidar a fim de aumentar a flexibilidade e gama de estilos como também desenvolver a capacidade de adaptabilidade para identificação do nível de prontidão de cada liderado e a escolha do estilo adequado, conscientes dos resultados positivos e negativos inerente a cada estilo.

Portanto, com base nas observações, discussões em grupo e resultados alcançados através da pesquisa de reação, pode-se afirmar que o uso da pesquisa empírica como método de ensino para desenvolvimento de competência de liderança no curso de Ciências Contábeis, como aplicado neste estudo de caso, apresenta-se como ótima alternativa dentre as metodologias de ensino disponíveis aos docentes de disciplinas das áreas humanas nos cursos de Ciências Contábeis, ressaltando-se como suas contribuições, a capacidade de oportunizar a vivencia real no contexto das organizações e possibilitar aos acadêmicos, a capacidade de avaliar criticamente os prós e contras dos comportamentos adotados quando no exercício profissional que demandar competências de líderes. A utilização de pesquisa empírica contribuiu também para a compreensão do complexo exercício que é liderar, gerando 
consciência e responsabilidade nos acadêmicos sobre o rol de competências a serem desenvolvidas pelo profissional, para ser qualificado como líder e não apenas como gestor, chefe ou gerente.

\section{REFERÊNCIAS}

ANDER-EGG, E. Introducción a las técnicas de investigación social: para trabajadores sociales. 7 ed. Buenos Aires: Humanitas, 1978.

BLANCHARD, Ken. Liderança de Alto Nível - como criar e liderar organizações de Alto Desempenho. Porto Alegre: Bookman, 2007.

BARBOSA, Ellen Borges. Reflexos do Pensamento de Foucault na Constituição da Cultura Escolar Brasileira. Revista Pandora Brasil - Edição especial No 4 - "Cultura e materialidade escolar" - 2011.

BIRCHAL, Fabiano Fernandes Serrano; VILELA, Cristina. Um Estudo Sobre O Modelo De Liderança Situacional de Paul Hersey e Kenneth Blanchard em uma Empresa Brasileira de Pequeno Porte. Book of Proceedings, 2012 (vol.2) ISBN 978-989-8472-25-0 (C) ESGHTUniversity of the Algarve, Portugal.

CARBONE, Pedro Paulo; BRANDÃO, Hugo Pena; LEITE, João Batista Diniz; VILHENA, Rosa Maria de Paula - Gestão por competências e gestão do conhecimento - 3. ed. - Rio de Janeiro: Editora FGV, 2009.

CAVALCANTI, Vera L.; CARPILOVSKY, Marcelo P.; LAGO, Regina A.; LUND, Myrian. Liderança e motivação. 2 ed. Rio de Janeiro: Editora FGV, 2007.

CRESWELL, J. Projeto de pesquisa: métodos qualitativo, quantitativo e misto. 3. ed. Porto Alegre: Booking:Artimed, 2010.

DUARTE, Ana Cléia de Souza. BARBOZA, Reginaldo José. Paulo Freire: O Papel da Educação Como Forma de Emancipação do Indivíduo. Revista Científica Eletrônica de Pedagogia - ISSN: 1678-300x. Ano V - Número 09 - Janeiro de 2007.

HAMEL, Gary \& PRAHALAD, C. K. Competindo pelo Futuro. Rio de Janeiro: Campus, 1995.

HERSEY, P.; BLANCHARD, K.H. Psicologia para administradores: a teoria e as técnicas da liderança situacional. Trad. Edwino A.Royer. São Paulo: Editora Pedagógica e Universitária, 1986.

MARIOTTI, Humberto. COMPLEXIDADE E PENSAMENTO COMPLEXO: BREVE INTRODUÇÃO E DESAFIOS ATUAIS. Publicado na Revista Portuguesa de Clínica Geral (Rev Port Clin Geral) 23: 727-731, 2007. 
MORIN, Edgar. Os sete saberes necessários à educação do futuro / Edgar Morin; tradução de Catarina Eleonora F. da Silva e Jeanne Sawaya ; revisão técnica de Edgard de Assis Carvalho. - 2. ed. - São Paulo : Cortez ; Brasília, DF : UNESCO, 2000. Disponível em http://www.juliotorres.ws/textos/textosdiversos/SeteSaberes-EdgarMorin.pdf, acesso em 20 de setembro de 2014.

MARION, Jose Carlos. Aspectos Sobre Metodologia do Ensino da Contabilidade (Negócios): A Arte de Ensinar. Palestra realizada no I Encontro dos Coordenadores do Curso de Ciências Contábeis de Rondônia, em 06 de junho de 2014.

PACHECO, Luzia. SCOFANO, Anna Cherubina. BECKERT, Mara. SOUZA, Valéria de. Capacitação e Desenvolvimento de Pessoas. 2. Ed - Rio de Janeiro: Editora FGV, 2009.

RETOUR, Didier et al. Competências Coletivas no Linear da Estratégia. Porto Alegre (RGS). Bookman, 2011.

SIENA, Osmar. Metodologia da pesquisa científica: elementos para elaboração e apresentação de trabalhos acadêmicos. Porto Velho: [s.n.], 2007.

SILVA, Valéria Louise de Araújo Maranhão Saturnino. ANDRADE, Robertson Carlos de. NETO, Odilon Saturnino Silva. O Desafio da Avaliação da Aprendizagem em Grandes Classes: uma Análise a partir da Percepção do Docente. XV SEMEAD, outubro de 2012. ISSN 2177-3866

SROUR, Robert Henry. PODER, CULTURA E ÉTICA NAS ORGANIZAÇÕES. Campos Elsevier. 3. ed. Formato EBook. 2013.

THEÓPHILO, Carlos Renato. Algumas reflexões sobre pesquisas empírica em contabilidade. Cad. estud. no.19 São Paulo Sept./Dec. 1998. ISSN 1413-9251

http://www.planalto.gov.br/ccivil_03/leis/19394.htm, acesso em 02 de junho 2014.

http://www.planalto.gov.br/ccivil_03/decreto-lei/Del9295.htm, acesso em 02 de junho 2014. 